\title{
PENJAMINAN MUTU PENDIDIKAN MELALUI TEKNOLOGI INFORMASI DI INSTITUT HINDU DHARMA NEGERI DENPASAR
}

\author{
Oleh : \\ I Gusti Ngurah Triyana \\ Institut Hindu Dharma Negeri Denpasar \\ ngrtriyana@gmail
}

Diterima 09 Januari 2017, direvisi 07 Januari 2017, diterbitkan 28 Pebruari 2017

\begin{abstract}
ABSTRAK
Institut Hindu Dharma Negeri (IHDN) Denpasar utilize information technology to support the vision and mission. Besides utilized to assist in the administration of education, information technology is also used for the development of quality IHDN. For example, the implementation of SPMI by the Lembaga Penjaminan Mutu (LPM) IHDN Denpasar by utilizing information technology in empowering educators, staff, service for learners. Information technology can make SPMI process becomes more transparent and accountable, so as to improve the quality of education in IHDN Denpasar.

In 2016, the lecturers of IHDN Denpasar have been using applications Beban Kerja Dosen (BKD) so that the implementation of the Tri Dharma Perguruan Tinggi of each Lecturer can be calculated in a professional manner. Application Beban Kerja Dosen (BKD) which uses Microsoft Access greatly assist the lecturers of IHDN Denpasar in preparing the report of BKD, which became the basis allowances of lecturer certification. Scientific Journal Publication as research journals have been managed by using information technology in website's form http:// www.ejournal.ihdn.ac.id. Process research and community service in IHDN Denpasar, ranging from proposals to reporting already using online application that Management Information Systems Institute of Research and Community Service (LPPM). Implementation of the obligations of officials in Denpasar IHDN in education have used the system of financial information which relating to applications such as SPAN and SILABI, and for IHDN affairs personnel data in Denpasar using http:// ropeg.kemenag.go.id information system. whereas for asset management or inventory in IHDN Denpasar is managed by using the application of State Property (BMN). Services to students, starting from recruitment of new students, the learning process through graduation in Denpasar IHDN also have been managed through a new Student Information System Admissions, Academic Information Systems, and Information Systems Graduation.
\end{abstract}

Keywords: Quality Assurance, Information Technology. 


\section{PENDAHULUAN}

Institusi pendidikan tinggi seperti Institut Hindu Dharma Negeri (IHDN) Denpasar yang berada dibawah naungan Kementerian Agama Republik Indonesia memiliki peran strategis dalam pembangunan nasional bangsa Indonesia. Pembangunan manusia Indonesia seutuhnya dapat diperjuangkan melalui penyelenggaraan pendidikan yang mutunya dapat terus ditingkatkan dari waktu ke waktu. Upaya peningkatan mutu dilakukan dengan memanfaatkan perkembangan teknologi informatika. Peranan teknologi yang pada esensinya adalah untuk mempermudah hidup manusia perlu mendapatkan perhatian khusus dalam rangka dipergunakan untuk berperan serta dalam usaha meningkatkan kualitas hidup masyarakat.

IHDN Denpasar memanfaatkan teknologi informasi untuk menunjang keberhasilan pencapaian visi dan misinya, yang berkaitan dengan tujuan Kementerian Agama khususnya dan bangsa Indonesia pada umumnya. Selain memanfaatkan teknologi yang sudah ada, IHDN Denpasar berperandalam pengembangan teknologi melalui penerapan teknologi informasi dengan sekaligus melakukan pengembangan atau pemberdayaan. Hal ini senada dengan arah kebijakan dan strategi kementerian pendidikan dan kebudayaan yang menyatakan bahwa"pusat penerapan teknologi di bidang pertanian, peternakan, perikanan, dan pengolahan hasil (pasca panen), industri manufaktur, ekonomi kreatif, dan jasa lainnya yang telah dikaji oleh lembaga penelitian, swasta, dan perguruan tinggi untuk diterapkan dalam skala ekonomi. (Renstra Kemendikbud 2015-2019, hal. 65)

Penerbitan Undang-Undang Nomor 12 Tahun 2012 tentang Pendidikan Tinggi (UU Dikti) mengokohkan Sistem Penjaminan Mutu Perguruan Tinggi yang telah dilaksanakan sejak tahun 2008. Walaupun dengan nama baru, yaitu Sistem Penjaminan Mutu Pendidikan Tinggi, sebagai sebuah sistem tetap mengintegrasikan tiga pilar di bawah ini.

- SistemPenjaminan Mutu Internal yang dilaksanakan oleh setiap perguruan tinggi;

- Sistem Penjaminan Mutu Eksternal atau Akreditasi yang dilaksanakan oleh Badan Akreditasi Perguruan Tinggi atau Lembaga Akreditasi Mandiri; dan

- Pangkalan Data Pendidikan Tinggi baik pada aras perguruan tinggi maupun arah Kementerian Riset, Teknologi, dan Pendidikan Tinggi. (Pedoman Sistem Penjaminan Mutu Pendidikan Tinggi, 2016, Direktorat Penjaminan Mutu Direktorat Jenderal Pembelajaran dan Kemahasiswaan Kementerian Riset, Teknologi, dan Pendidikan Tinggi, hal iv)

Pengertian Sistem Penjaminan Mutu Internal Sebagaimana ditetapkan dalam Pasal 53 UU Dikti, SPM Dikti terdiri atas SPMI dan SPME atau akreditasi. SPMI adalah kegiatan sistemik penjaminan mutu pendidikan tinggi oleh setiap perguruan tinggi secara otonom atau mandiri untuk mengendalikan dan meningkatkan penyelenggaraan pendidikan tinggi secara berencana dan berkelanjutan. Dengan demikian, setiap perguruan tinggi dapat mengembangkan sendiri SPMI antara lain sesuai dengan latar belakang sejarah, nilai dasar yang menjiwai pendirian perguruan tinggi itu, jumlah program studi dan sumber daya manusia, sarana dan prasarana perguruan tinggi tersebut tanpa campur tangan pihak lain. Sebagai contoh, SPMI di universitas tidak cocok diimplementasikan di sekolah tinggi. Demikian pula, SPMI di perguruan tinggi kelas dunia tidak cocok digunakan di perguruan tinggi dengan visi lokal. Sekalipun setiap perguruan tinggi dapat mengembangkan SPMI secara otonom atau mandiri, namun terdapat hal mendasar yang harus ada di dalam SPMI setiap perguruan tinggi. Di dalam Pasal 52 ayat (2) UU Dikti 
disebutkan bahwa penjaminan mutu dilakukan melalui 5 (lima) langkah utama yang disingkat PPEPP, yaitu Penetapan, Pelaksanaan, Evaluasi (pelaksanaan), Pengendalian (pelaksanaan), dan Peningkatan Standar Dikti. Hal ini berarti bahwa kelima langkah utama tersebut harus ada dalam melaksanakan SPMI, bahkan merupakan hal terpenting dari SPMI di setiap perguruan tinggi. Sesuai dengan istilah 'internal' di dalam SPMI, kelima langkah tersebut harus dilaksanakan secara internal oleh perguruan tinggi.

Sistem Penjaminan Mutu Internal (SPMI) terhadap pelaksanaan Standar Dikti dalam SPMI di suatu perguruan tinggi tidak dapat dilakukan oleh lembaga lain di luar perguruan tinggi tersebut sekalipun lembaga tersebut dipandang kredibel. Pihak eksternal dapat dilibatkan bukan dalam SPMI melainkan dalam SPME, yaitu melalui proses akreditasi. Akreditasi perguruan tinggi dilaksanakan oleh BAN-PT, sedangkan akreditasi program studi dilaksanakan oleh LAM. Perguruan tinggi dapat pula meminta akreditasi ke lembaga internasional seperti ABET untuk rumpun ilmu teknik.

Lima langkah utama di dalam SPMI suatu perguruan tinggi berkaitan erat dengan standar di dalam SPMI. Menurut Pasal 54 UU Dikti, standar yang harus digunakan di dalam SPMI setiap perguruan tinggi adalah SN Dikti yang ditetapkan oleh Menteri dan Standar Dikti yang ditetapkan oleh setiap perguruan tinggi dengan mengacu pada SN Dikti. SN Dikti merupakan satuan standar yang meliputi Standar Nasional Pendidikan ditambah dengan Standar Nasional Penelitian, dan Standar Nasional Pengabdian Kepada Masyarakat. Sementara itu, Standar Dikti yang ditetapkan oleh setiap perguruan tinggi terdiri atas sejumlah standar dalam bidang akademik dan bidang nonakademik yang melampaui SN Dikti. (Pedoman Sistem Penjaminan Mutu Pendidikan Tinggi, 2016, Direktorat Penjaminan Mutu Direktorat Jenderal Pembelajaran dan Kemahasiswaan
Kementerian Riset, Teknologi, dan Pendidikan Tinggi, hal 21)

Penerapan SPMI oleh Lembaga Penjamin Mutu (LPM) IHDN Denpasar peranannya sangat strategis dengan memanfaatkan teknologi informasi dalam memberdayakan tenaga pendidik, tenaga kependidikan, pelayanan kepada peserta didik. Teknologi Informasi dapat membuat proses SPMI menjadi lebih transfaran dan dapat dipertanggungjawabkan. Hal ini tentukan akan mampu meningkatkan integritas IHDN Denpasar sebagai lembaga pendidikan tinggi dalam ikut berperan serta meningkatkan kualitas pendidikan anak-anak bangsa.

Tulisan ini membahas tentang penerapa teknologi informasi untuk menjamin mutu di Institut Hindu Dharma Negeri (IHDN) Denpasar.

\section{PEMBAHASAN}

Asmani (2011: 145-149) menyatakan bahwa pemanfaatan Teknologi Informasi dalam bidang pendidikan meliputi:

1) Berbagi hasil penelitian.

2) Konsultasi dengan pakar.

3) Perpustakaan online.

4) Diskusi online, dan

5) Kelas online.

Berhubungan dengan hal tersebut, maka pemanfaatan teknologi informasidi IHDN Denpasar dapat diarahkan untuk terwujudnya sharing penelitian secara online, diskusi online, kelas online dan perpustakaan online. Diskusi online sudah menjadi kebiasaan bagi para dosen IHDN Denpasar melalui media sosial, di masa yang akan datang dapat dikembangkan sebuah website yang memfasilitasi diskusi online khusunya dengan para pakar atau para dosen IHDN Denpasar.

Hal tersebut agak berbeda namun selaras dengan pendapat Alavi dan Gallupe (Mulyanta dan Leong, 2009: 20) yang mengungkapkan bahwa tujuan dan peranan teknologi informasi dalam pendidikan antara lain adalah: 
1) Memperbaiki competitive positioning.

2) Meningkatkan brand image

3) Meningkatkan kualitas pembelajaran dan pengajaran

4) Meningkatkan kepuasan siswa/ mahasiswa.

5) Meningkatkan pendapatan.

6) Memperluas basis siswa/mahasiswa.

7) Meningkatkan kualitas pelayanan.

8) Mengurangi biaya operasi.

9) Mengembangkan produk dan layanan baru.

Dari sisi pemanfaatan teknologi informasi sebagai suatu keterampilan dan kompetensi dapat diperoleh penjelasan lanjut bahwa:

1) Setiap pemangku kepentingan harus memiliki kompetensi dan keahlian menggunakan teknologi informasi dan komunikasi untuk pendidikan.

2) Informasi merupakan "bahan mentah" dari pengetahuan yang harus diolah melalui proses pembelajaran.

3) Membagi pengetahuan antara satu siswa/mahasiswa dengan yang lainnya, bersifat mutlak dan tidak berkesudahan.

4) Belajar mengenai bagaimana cara belajar yang efektif dan efisien bagi pengajar/dosen, siswa/mahasiswa , dan stakeholder.

5) Belajar adalah proses seumur hidup yang berlaku bagi setiap individu. Dengan demikian berbagai informasi yang telah diperoleh oleh mahasiswa dalam pencariannya memanfaatkan teknologi informasi masih berupa "bahan mentah" yang masih harus diolah melalui proses pembelajaran.

Teknologi Informasi sebagai infrastruktur pembelajaran meliputi:

1) Bahan ajar yang telah banyak disimpan dalam format digital dengan model yang beragam seperti multimedia,
2) Mahasiswa dan dosen secara aktif bergerak dari satu tempat ke tempat lain,

3) Proses pembelajaran seharusnya dapat dilakukan di mana dan kapan saja,

4) Perbedaan letak geografi tidak menjadi batasan pembelajaran,

5) The network is the school akan menjadi fenomena baru dalam dunia pendidikan.

Mulyanta dan Leong (2009: 40) mengemukakan sepuluh peranan Teknologi Informasi sebagai sumber bahan ajar, yaitu

1) Sumber ilmu pengetahuan,

2) Tempat bertemunya para pembelajar,

3) Melahirkan inisiatif dalam kegiatan belajarmengajar,

4) Alat pendukung mengatasi keterbatasan pancaindera,

5) Bagian yang tidak terpisahkan dari kerangka kurikulum,

6) Penyeimbang gaya belajar individu,

7) Pengelolaan Institusi Pendidikan,

8) Pengelola Institusi Pendidikan,

9) Menjadi instrukturinstitusi pendidikan, dan

10) Mengubahinstitusi pendidikan menjadi pusat unggulan. Selain dampak positif / keunggulan yang telah dikemukakan tersebut teknologi informasi juga memiliki dampak negatif yang harus diperhatikan dan mendapatkan antisipasi.

Asmani (2011: 140) menyatakan beberapa dampak negatif dari pemanfaatan teknologi informasi di dunia pendidikan antara lain:

1) Mahasiswa dapat menjadi pecandu keberadaan dunia maya secara berlebihan. Hal tersebut dapat terjadi ketika mahasiswa tidak memiliki sikap skeptik serta kritis terhadap sesuatu hal baru. Di dalam dunia maya (internet) mereka secara tidak 
langsung telah masuk di dalam dunia yang over free, menjadi perlu dan penting adanya sikap skeptik dan kritis untuk menjadi benteng atau filter dari segala sumber informasi yang ada. Selain itu, adanya perhatian dari orang tua yang sangat berperan dalam menanamkan nilai-nilai tentang sebuah norma agama sebagai landasan hidup.

2) Tindakan kriminal (Cyber Crime). Di dalam dunia pendidikan yang seharusnya segala sesuatunya dapat dipertanggungjawabkan secarailmiah hal ini pun dapat terjadi, misalnya pencurian dokumen atau asset penting tentang sebuah tatanan pendidikan yang sesungguhnya dirahasiakan (dokumen mengenai ujian akhir atau negara) melalui media internet.

3) Menimbulkan sikap yang apatis pada masing-masing individu, baik bagi mahasiswa maupun dosen.

Berhubungan dengan apa yang telah diuraikan diatas, Andika (2012: 5) dan Yahya (2011: 10) mengemukakan bahwa dalam pemanfaatan teknologi informasi dilakukan dengan bijak, antara lain:

1) Tidak menjadikan teknologi informasi dan komunikasi sebagai media atau satusatunya sarana dalam pembelajaran, misalnya tidak hanya mendownload e-book, tetapi masih tetap membeli buku-buku cetak, tidak hanya berkunjung ke digital library namun juga masih berkunjung ke perpustakaan.

2) Pihak pengajar (dosen) maupun orang tua memberikan pembelajaran etika dalam berteknologi informasi dan komunikasi agar dapat dipergunakan secara optimal tanpa menghilangkan etika.

3) Pemerintah sebagai pengendali sistemsistem informasi seharusnya lebih peka dan menyaring informasi apa saja yang dapat di akses di dunia maya.

4) Menegakkan fungsi hukum yang berlaku, misalnya pembentukan cyber task yang bertugas untuk menentukan standar operasi penegndalian dalam penerapan teknologi informasi. Hal ini meliputi keamanan teknologi, sistem rekap data, serta fungsi pusat penanganan bencana.

Wotruba dan Wright (1975) seperti dikutip Miarso (2009: 25) menyebutkan tujuh indikator pembelajaran yang efektif yaitu:

1) Pengorganisasian kuliah dengan baik.

2) Komunikasi berlangsung efektif. Indikator suatu komunikasi telah berlangsung dengan efektif adalah informasi yang disampaikan oleh dosen dapat dipahami, jelas dan tepat. Penggunaan media dan teknik komunikasi dapat menarik perhatian mahasiswa merupakan karakteristik dari efektifitas komunikasi pembelajaran. Kompetensi perkuliahan perlu dikuasai oleh semua pendidik. Secara umum pendidik wajib mampu menciptakan situasi menyenangkan.

3) Penguasaan dan antusiasme dalam mata kuliah, Penguasaan dan antusiasme dalam mata kuliah. Setiap dosen dituntut memiliki kompetensi di bidangnya, sehingga menguasai materi perkuliahannya agar dapat diorganisir secara sistematis dan logis.

4) Sikap positif terhadap mahasiswa, Sikap positif terhadap mahasiswa tercermin dalam berbagai hal. Sebagai contoh bagaimana sikap dosen saat mahasiswa mengalami kesulitan belajar, apakah dosen menyediakan waktu untuk menerima konsultasi di luar kelas pembelajaran. Dalam hal ini peran teknologi informasi dapat menjadi jembatan, namun etika dalam 
mempergunakannya tidak boleh ditinggalkan.

5) Pemberian ujian dan nilai yang adil, Adil di dalam ujian dan penilaian.

6) keluwesan dalam pendekatan pengajaran, Keluwesan dalam pendekatan pengajaran. Variasi pendekatan yang digunakan dalam pembelajaran menjadi salah satu nilai tambah dosen. Pola mengajar yang bervariasi besar kemungkinan bermanfaat dalam mencapai berbagai tujuan, atau menanggapi latar belakang dan kemampuan mahasiswa. Umpamanya simulasi dan teknik permainan dapat dimanfaatkan dalam mengajar analisa, sintesa dan kemampuan berpikir kritis. Media dipakai untuk menambah daya cerna kuliah sehingga memudahkan mahasiswa menangkap pesan pembelajaran.

7) Hasil mahasiswa yang baik. Hasil belajar mahasiswar dipengaruhi oleh berbagai faktor dan tidak semuanya berhubungan dengan dosen. Kemampuan dan motivasi misalnya, sangat berhubungan dengan apa yang dicapai mahasiswa. Adalah penting untuk mempertimbangkan usaha belajar mahasiswa pada saat menilai efektivitas pembelajaran.

\section{a. Teknologi Informasi Untuk Dosen}

Kewajiban melaksanakan Tri Dharma Perguruan Tinggi bagi para dosen dapat dijamin keberhasilannya apabila ada indikator yang jelas dan sesuai dengan regulasi yang berlaku. Indikator-indikator tersebut menjadi acuan dalam penerapan teknologi informasi untuk menunjang pekerjaan dilakukan secara efektif dan efisien. Pada tahun 2016 ini para dosen di IHDN Denpasar telah menggunakan beberapa aplikasi untuk menjaga agar kewajiban dalam melaksanakan Tri Dharma Perguruan Tinggi dapat direkapitulasi dan dihitung secara profesional. Aplikasi Beban Kerja Dosen (BKD) yang menggunakan Microsoft Acces sangat membantu para dosen IHDN Denpasar dalam menyusun laporan BKD, yang menjadi dasar dapat dibayarkannya tunjangan sertifikasi dosen.

Publikasi karya ilmiah berupa jurnal penelitian telah dikelola menggunakan teknologi informasi dalam bentuk website http:// www.ejournal.ihdn.ac.id . Dengan adanyanya website berbasis ojs ini para dosen di IHDN Denpasar dapat mempublikasikan karya ilmiahnya secara online, dimana ini menjadi syarat karya ilmiah ini dapat diakui secara sah untuk pemenuhan kewajiban BKD maupun kenaikan pangkat akademik. Beberapa jurnal yang dikelola oleh masing-masing jurusan yang ada di IHDN Denpasar telah diunggah dan dapat diunduh melalui jurnal elektronik ini.

Proses penelitian dan pengabdian masyarakat di IHDN Denpasar, mulai dari pengajuan proposal sampai pelaporan sudah dimulai dengan memanfaatkan aplikasi online yaitu Sistem Informasi Manajemen Lembaga Penelitian dan Pengabdian Masyarakat (LPPM). Penggunaan sistem informasi ini diharapkan dapat mengatur proses penelitian dan pengabdian masyarakat sesuai dengan padoman yang telah ditetapkan. Sistem informasi ini juga akan memudahkan para stakeholder untuk mendapatkan informasi mengenai penelitian dan pengabdian pada masyarakat. Laporan rekalitulasi penelitian dan pengabdian masyarakat pun akan menjadi lebih mudah dibuat dan akan memberikan informasi atau peta mengenai penelitian dan pengabdian masyarakat apa saja yang telah dilakukan oleh para dosen di IHDN Denpasar. Sistem Informasi ini juga akan memudahkan LPPM untuk memberikan keputusan menyetujui atau tidak menyetujuan proposal penelitian dan pengabdian masyarakat yang diajukan oleh para dosen, mengingat dengan adanya system informasi ini LPPM akan mudah mengecek 
plagiasi penelitian karena semua data mengenai penelitian dosen IHDN Denpasar akan disimpan dalam satu database. Pengabdian masyarakat pun dapat direncanakan dengan lebih baik, sehingga azas pemerataan dan keadilan pun dapat diwujudkan.

Sistem Informasi Manajemen LPPM juga disinkronisasikan dengan Sistem Repositori Dosen dan Sistem Repositori Mahasiswa. Sistem Repositori Dosen menjadi tempat penyimpannan dan pengelolaan karya ilmiah para dosen di IHDN Denpasar, sedangkan Sistem Repositori Mahasiswa menjadi tempat penyimpanan dan pengelolaan karyailmiah yang dihasilkan oleh para mahasisiswa di IHDN Denpasar. Adanya sistem informasi ini memudahkan untuk mnghindari plagiasi karena semua data mengenai karya ilmiah dosen dan mahasiswa telah disimpan di masing-masing database.

\section{b. Teknologi Informasi Untuk Para Pegawai}

Pelaksanaan kewajiban para pegawai di IHDN Denpasar dalam penyelenggaraan pendidikan juga telah ditunjang teknologi informasi. Bagian keuangan telah menggunakan sistem informasi yang berkaitan dengan keuangan seperti Aplikasi SPAN dan SILABI yang digunakan untuk mengelola setiap pembayaran atau pengeluaran uang. Aplikasi ini digunakan oleh bendahara pengeluaran dan gaji IHDN Denpasar. Dengan adanya aplikasi ini pembayaran gaji para dosen dan pegawai di IHDN Denpasar dan pengeluaran lainnya yang berkaitan dengan penyelenggaraan pendidikan dapat dilakukan secara profesional.

Urusan data kepegawaian di IHDN Denpasar menggunakan sistem informasi http:/ /ropeg.kemenag.go.id. Sistem informasi ini mengelola data kepegawaian mualai dari input data pegawai baru, edit atau update data, dan pembuatan laporan data masing-masing pegawai sekaligus rekapitulasi laporan data kepegawaian IHDN Denpasar. Penggunaan sistem informasi ini juga memudahkan kementerian agama untuk mengakses data kepegawaian IHDN Denpasar.

Pengelolaan aset atau barang inventaris IHDN Denpasar juga dikelola dengan memanfaatkan teknologi informasi yaitu aplikasi Barang Milik Negara (BMN). Aplikasi ini mencatat seluruh inventaris yang dimiliki oleh Negara, juga dapat digunakan untuk mengupdate status barang inventaris yang ada pada database, serta dapat diperoleh laporan mengenai rekapitulasi barang inventaris milik Negara yang ada pada IHDN Denpasar.

\section{c. Teknologi Informasi Untuk Mahasiswa}

Penyelenggaran pendidikan yang dimulai dari perekrutan mahasiswa baru, proses pembelajaran sampai dengan kelulusan mahasiswa di IHDN Denpasar juga telah dikelola dengan memanfaatkan teknologi Informasi. Penerimaan mahasiswa baru di IHDN Denpasar telah dilakukan secara online mulai tahun 2014, walaupun masih ada banyak kekurangan yang disebabkan faktor dari pengelola akademik maupun masalah dari masyarakat sebagai pengguna layanan pendidikan. Pendaftaran mahasiswa baru di IHDN Denpasar mulai tahun 2016 telah menggunakan Sistem Informasi Penerimaan Mahasiswa Baru (SIMABA). Pengelolaan proses akademik mulai dari heregistrasi, pengisian Kartu Rencana Studi (KRS), pembagian jadwal kuliah juga telah dirancang dengan menggunakan Sistem Informasi Akademik. Mahasiswa dapat melihat biodatanya, jadwal kuliah, dan nilainya sendiri melalui Sistem Informasi Online (SION).

Setelah proses pembelajaran selesai, untuk kelulusan mahasiswa telah disiapkan Sistem Informasi Wisuda sehingga data alumni dapat dihinpun secara otomatis. Melalui semua layanan sistem informasi ini diharapkan dapat 
meningkatkan mutu layanan pendidikan kepada masyarakat, sehingga akan berujung pada mutu pendidikan itu sendiri.

\section{SIMPULAN}

Penjaminan mutu pendidikan adalah suatu keniscayaan yang wajib dilakukan oleh IHDN Denpasar dengan menerapkan Sistem Penjaminan Mutu Internal dan Sistem Penjaminan Mutu Eksternal. Perencanaan, pelaksanaan, evaluasi dan pelaporan penjaminan mutu ini sangat ditunjang oleh kemampuan untuk memberdayakan sumber daya yang ada di IHDN Denpasar baik itu sumber daya manusia, sumber daya berupa sarana dan prasarana termasuk sumber daya teknologi yang telah ada, dan yang akan dirancang untuk masa yang akan datang.

IHDN Denpasar dalam menyelenggarakan pendidikan tinggi keagamaan Hindu telah memanfaatkan teknologi informasi untuk menunjang kelancaran pelaksanaan tugas dan fungsi institusi secara profesional. Penggunaan teknologi informasi sangat membantu dalam menjamin mutu bahkan meningkatkan mutu setiap proses pendidikan yang berlangsung di IHDN Denpasar

\section{SARAN}

Pada masa yang akan datang dapat segera dirancang pemanfaatkan teknologi informasi lainnya seperti kelas online, perpustakaan onlne, dan kenaikan pangkat online untuk para dosen dan pegawai.

\section{DAFTAR PUSTAKA}

Jamal Makmur Asmani, 2011, Tips Efektif Pemanfaatan Teknologi Informasi dan Komunikasi dalam Dunia Pendidikan, Diva Press. Yogyakarta.

Mulyanta dan Marlon Leong, 2009, Membangun Multimedia Interaktif; Media Pembelajaran, Universitas Atma Jaya. Yogyakarta.

Pedoman Sistem Penjaminan Mutu Pendidikan Tinggi, 2016, Direktorat Penjaminan Mutu Direktorat Jenderal Pembelajaran dan Kemahasiswaan Kementerian Riset, Teknologi, dan Pendidikan Tinggi

Renstra Kemendikbud 2015-2019.

Undang-Undang Nomor 12 Tahun 2012 tentang Pendidikan Tinggi.

Yusufhadi Miarso, 2009, Menyemai Benih Teknologi Pendidikan, Cet. 4, Diterbitkan atas kerjasama dengan Pusat Teknologi Komunikasi dan Informasi Pendidikan PUSTEKKOM DIKNAS). 